Lestaw Ladniak

Politechnika Wroctawska

Wydziat Elektryczny

Instytut Podstaw Elektrotechniki i Elektrotechnologii

\title{
Wpływ układu połączeń transformatora trakcyjnego na niesymetrię napięć w sieci zasilającej
}

\begin{abstract}
Bazujac na przyjętych modelach układów połaczeń uzwojeń transformatorów stosowanych do zasilania trakcji kolei dużych prędkości przeprowadzono ocenę wpływu chwilowych zmian napięć na zaciskach pierwotnych tych transformatorów w zależności od stopnia obciażenia strony wtórnej. Zaproponowane równania i przyjęte współczynniki umożliwiaja wyznaczenie wartości napięć niesymetrii w sieci zasilajacej, co jest bardzo istotne przy podejmowaniu decyzji o wyborze odpowiedniego typu transformatora do danych warunków zasilania.
\end{abstract}

\section{WPROWADZENIE}

Do zasilania układów trakcji kolei dużych prędkości, gdy moc pociagu jest rzędu $10 \mathrm{MW}$, stosowany jest obecnie najczęściej system $2 \times 25 \mathrm{kV}$ napięcia przemiennego $\mathrm{z}$ autotransformatorami. Zasadniczym elementem takiego układu zasilania jest transformator, w którym następuje przekształcenie trójfazowego układu napięć zasilających na układ dwufazowy. W zależności od zastosowanego układu polaczeń uzwojeń pierwotnych i wtórnych uzyskuje się dwa sinusoidalnie zmienne przesunięte względem siebie napięcia.

Niezależnie od liczby uzwojeń wtórnych transformatora oraz zastosowanego układu połączeń uzwojeń pierwotnych i wtórnych tego transformatorów do zasilającego systemu energetycznego jest wprowadzana niesymetria napięć i prądów $[1,2]$. Wynika to $\mathrm{z}$ faktu, że przyłączone do dwóch faz strony wtórnej transformatora obciążenie jest niesymetryczne, ponieważ zasilane są dwie różne sekcje sieci trakcyjnej z różną liczbą pojazdów o różnym $\mathrm{w}$ danej chwili stopniu obciążenia. Miarą wprowadzanej do energetycznego systemu zasilającego niesymetrii $\varepsilon_{u}$ jest wyrażony w procentach stosunek skutecznych wartości składowej przeciwnej napięcia $U_{2}$ do składowej zgodnej napięcia $U_{l}$ :

$$
\varepsilon_{u}=\frac{U_{2}}{U_{1}} 100 \%
$$

W artykule opisano wpływ stosowanych obecnie układów połączeń transformatorów zasilających sieć trakcji kolei dużych prędkości na poziom odkształceń napięć $\mathrm{w}$ zasilającym systemie energetycznym.

\section{UKŁADY POŁĄCZEŃ TRANSFORMATORÓW TRAK- CYJNYCH}

Powszechnie znanym i od dawna stosowanym transformatorem służącym do transformacji napięć układu trójfazowego na dwufazowy układ napięć jest transformator Scotta, w którym napięcia strony wtórnej są przesunięte względem siebie o kąt $90^{\circ}$. Korzystając z rozwiązań, w których zastosowano połączenie uzwojeń gwiazd-trójkąt lub uzwojenia transformatora są połączenie w otwarty trójkąt uzyskujemy na wyjściu transformatora napięcia przesunięte o krotność kąta $120^{\circ}$. W skrajnym przypadku układy trakcji kolejowej można zasilić poprzez dwa transformatory jednofazowe lub transformator $\mathrm{z}$ dzielonym przeciwsobnie połą-czonymi uzwojeniami wtórnymi, w którym napięcia są przesunięte o kąt $180^{\circ}$. Do transformacji napięć dla potrzeb układów zasilania trakcji kolejowej stosowane są też bardziej złożone układy połączeń uzwojeń, takie jak Le Blanc'a lub Woodbridge'a. Z nowszych rozwiązań na uwagę zasługuje stosowane w Japonii połączenie Roof-Delta [3]. Każdy z tych układów zasilających ma swoje wady i zalety. Różne są też właściwości i charakterystyki tych rozwiązań. To wszystko powoduje, że w różnym stopniu przenoszone są do zasilającej sieci energetycznej wszelkiego rodzaju zakłócenia i niesymetrie obciążeń. W tabeli 1 zestawiono podstawowe równania opisujące relację między napięciami i prądami strony pierwotnej i wtórnej transformatorów o różnych układach połączeń tych uzwojeń [4]. W celu uproszczenia rozważań przyjęto, że rozpatrywane transformatory są idealne, a współczynnik mocy poszczególnych uzwojeń wtórnych jest równy jedności. 
Tabela 1.

Równania napięciowe i prądowe transformatorów trakcyjnych

\begin{tabular}{|c|c|c|}
\hline Układ połączeń uzwojeń transformatora & Równania napięciowe & Równania prądowe \\
\hline 1. Pojedyncze dzielone & $\begin{array}{l}n u_{x}=u_{A B} \\
n u_{y}=-u_{A B}\end{array}$ & $\begin{array}{l}n i_{A}=i_{x}+i_{y} \\
\left.n i_{B}=-i_{x}-i_{y}\right)\end{array}$ \\
\hline 2. Otwarty trójkąt VV & $\begin{array}{l}n u_{x}=u_{C B} \\
n u_{y}=u_{A B}\end{array}$ & $\begin{array}{l}n i_{A}=i_{y} \\
n i_{B}=-i_{x}-i_{y} \\
n i_{C}=i_{x}\end{array}$ \\
\hline 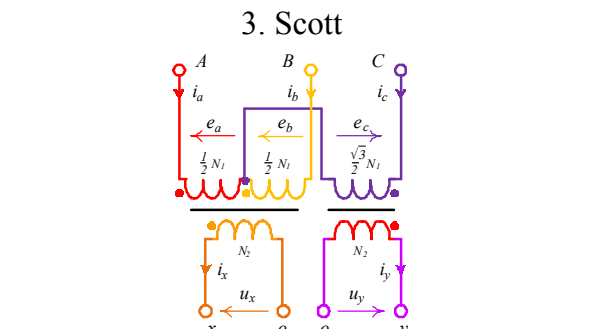 & $\begin{array}{l}n u_{x}=u_{a b} \\
n u_{y}=-\frac{2}{\sqrt{3}} u_{b c}+\frac{1}{2} u_{a b}\end{array}$ & $\begin{array}{l}n i_{a}=i_{x}-\frac{1}{\sqrt{3}} i_{y} \\
n i_{b}=-i_{x}-\frac{1}{\sqrt{3}} i_{y} \\
n i_{c}=\frac{2}{\sqrt{3}} i_{y}\end{array}$ \\
\hline 4. Le Blanc & $\begin{array}{l}n u_{x}=\frac{\sqrt{3}}{3}\left(u_{A B}-u_{C A}\right) \\
n u_{y}=\frac{1}{3}\left(u_{A B}+u_{C A}-2 u_{B C}\right)\end{array}$ & $\begin{array}{l}n i_{A}=-\frac{2}{\sqrt{3}} i_{x} \\
n i_{B}=\frac{1}{\sqrt{3}} i_{x}+i_{y} \\
n i_{C}=\frac{1}{\sqrt{3}} i_{x}-i_{y}\end{array}$ \\
\hline 5. Woodbridge & $\begin{array}{l}n u_{x}=u_{a}-u_{b} \\
n u_{y}=\frac{2 N_{S}+N_{C}}{N_{C}} u_{c}=\sqrt{3} u_{c}\end{array}$ & $\begin{array}{l}n i_{A}=\frac{2}{\sqrt{3}} i_{x} \\
n i_{B}=-\frac{1}{\sqrt{3}} i_{x}-i_{y} \\
n i_{C}=-\frac{1}{\sqrt{3}} i_{x}+i_{y}\end{array}$ \\
\hline 6. Gwiazda-trójkąt $\mathrm{Yd}$ & $\begin{array}{l}n u_{x}=u_{A} \\
n u_{y}=-u_{B}\end{array}$ & $\begin{array}{l}n i_{A}=\frac{2}{3} i_{x}+\frac{1}{3} i_{y} \\
n i_{B}=-\frac{1}{3} i_{x}-\frac{2}{3} i_{y} \\
n i_{C}=-\frac{1}{3} i_{x}+\frac{1}{3} i_{y}\end{array}$ \\
\hline 7. Roof-delta & $\begin{array}{l}n u_{x}=\frac{1}{3}\left(-u_{A}+2 u_{B}-u_{C}\right) \\
n u_{y}=\frac{1}{\sqrt{3}}\left(u_{A}-u_{C}\right)\end{array}$ & $\begin{array}{l}n i_{A}=\frac{1}{3}\left(-i_{x}+\sqrt{3} i_{y}\right) \\
n i_{B}=\frac{1}{3} 2 i_{x} \\
n i_{C}=\frac{1}{3}\left(-i_{x}-\sqrt{3} i_{y}\right)\end{array}$ \\
\hline
\end{tabular}

\section{RÓWNANIE MOCY TRANSFORMATORA}

Moc skuteczna $S_{T}$ transformatora zasilającego obwody trakcji kolejowej jest sumą maksymalnych wartości mocy skutecznych $S_{x}$ oraz $S_{y}$ poszczególnych uzwojeń wtórnych tego transformatora. Oczywiście maksymalna moc skuteczna obciążenia transformatora $S_{T}$ nie powinna przekraczać znamionowej mocy transformatora $S_{N}$. W związku z tym, moc poszczególnych uzwojeń wtórnych transformatora można opisać korzystając ze współczynnika $K$ określającego stopień obciążenia jednego z tych uzwojeń:

$$
S_{x}=K S_{T} \text { oraz } S_{y}=S_{T}-S_{x}=(1-K) S_{T}
$$


Ponieważ moc skuteczną poszczególnych uzwojeń strony wtórnej transformatora można wyrazić w zależności od wartości admitancji obciążenia $Y_{x}, Y_{y}$ oraz wartości napięć $U_{x}, U_{y}$, to przy założeniu równości modułów napięć strony wtórnej transformatora możemy napisać:

$$
\underline{S}=\underline{Y}_{x} U_{x}^{2}+\underline{Y}_{y} U_{y}^{2}=\underline{Y}_{x} U_{x}^{2}+\underline{Y}_{y} U_{x}^{2} e^{j 2 \phi}=\left(\underline{Y}_{x}+\underline{Y}_{y} e^{j 2 \phi}\right) U_{x}^{2}
$$

gdzie $\phi$ jest kątem przesunięcia między napięciami strony wtórnej transformatora.

Jeżeli przyjmiemy wskaz napięcia $\underline{U}_{x}$ za wielkość odniesienia, to moc skuteczną transformatora $S$ w zależności od modułów mocy poszczególnych uzwojeń strony wtórnej oraz współczynnika $K$ opisuje następujące równanie:

$\underline{S}=K S_{T}+(1-K) S_{T}^{e j 2 \phi}=S_{T}\left(K-K e^{j 2 \phi}+e^{j 2 \phi}\right)$

Jak wynika z zależności (5) o szybkości przekazywania energii przez transformator zasilający trakcję kolei dużych prędkości decyduje nie tylko stopień obciążenia poszczególnych faz strony wtórnej tego transformatora, ale przede wszystkim kąt przesunięcia między napięciami fazowymi strony wtórnej transformatora.

Wartości kąta przesunięcia napięć wtórnych oraz równania opisujące współczynniki szybkości przekazywania energii dla poszczególnych układów połączeń uzwojeń transformatorów zawiera tabela 2.

\section{WSPÓŁCZYNNIK ASYMETRII NAPIĘĆ}

Korzystając $\mathrm{z}$ podanych $\mathrm{w}$ tabeli 1 równań oraz metody składowych symetrycznych można uzyskać równania opisujące relację między składową przeciwną napięcia, a składową zgodną tego napięcia w zależności od mocy transformatora oraz mocy zwarciowej sytemu w miejscu przyłączenia transformatora do zasilającej go sieci energetycznej. W tym celu rozpatrzmy typowy przypadek, gdy uzwojenia transformatora trakcyjnego są połaczone $\mathrm{w}$ tak zwany otwarty trójkąt (VV), a do uzwojeń wtórnych przyłączono admitancje obciążenia $Y_{x L}$ oraz $Y_{y L}$.

W stanie ustalonym przy wymuszeniu sinusoidalnym relację między napięciami a prądami po stronie pierwotnej rozpatrywanego transformatora są opisane następującymi równaniami:

$$
\left[\begin{array}{l}
\underline{I}_{A} \\
\underline{I}_{B} \\
\underline{I}_{C}
\end{array}\right]=\frac{1}{n}\left[\begin{array}{cc}
0 & 1 \\
-1 & -1 \\
1 & 0
\end{array}\right]\left[\begin{array}{l}
\underline{Y}_{x L} \\
\underline{Y}_{y L}
\end{array}\right] \frac{1}{n}\left[\begin{array}{ccc}
0 & -1 & 1 \\
1 & -1 & 0
\end{array}\right]\left[\begin{array}{l}
\underline{U}_{A} \\
\underline{U}_{B} \\
\underline{U}_{C}
\end{array}\right]
$$

Przyjmując, że $\frac{1}{n^{2}} \underline{Y}_{x L}=\underline{Y}_{x}$ oraz $\frac{1}{n^{2}} \underline{Y}_{y L}=\underline{Y}_{y}$ oraz korzystając z przekształcenia wielkości fazowych na składowe symetryczne otrzymujemy:

$$
\left[\begin{array}{l}
\underline{I}_{o} \\
\underline{I}_{1} \\
\underline{I}_{2}
\end{array}\right]=\left[\begin{array}{ccc}
0 & 0 & 0 \\
0 & \underline{Y}_{x}+\underline{Y}_{y} & -\underline{Y}_{x}-a \underline{Y}_{y} \\
0 & -\underline{Y}_{x}-a^{2} \underline{Y}_{y} & \underline{Y}_{x}+\underline{Y}_{y}
\end{array}\right]\left[\begin{array}{l}
\underline{U}_{o} \\
\underline{U}_{1} \\
\underline{U}_{2}
\end{array}\right]
$$

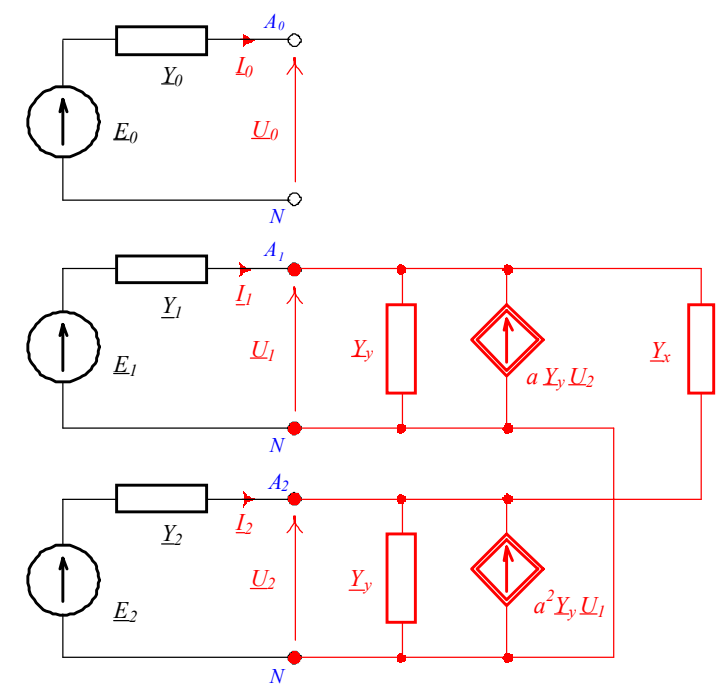

Rys.2. Układ połączeń obwodów składowych symetrycznych dla transformatora V-V

Korzystając z prądowego prawa Kirchhoffa dla węzła $A_{2}$ oraz przyjmując, że źródło napięć zasilających jest symetryczne, to otrzymujemy następującą równość:

$$
\underline{U}_{2}\left(\underline{Y}_{s}+\underline{Y}_{x}+\underline{Y}_{y}\right)=\underline{U}_{1}\left(\underline{Y}_{x}+a^{2} \underline{Y}_{x}\right)
$$

Jak wynika z powyższego równania stosunek składowej przeciwnej napięcia $U_{2}$ do składowej zgodnej napięcia $U_{1}$ jest opisany następującym równaniem:

$$
\frac{\underline{U}_{2}}{\underline{U}_{1}}=-\frac{Y_{x}+a^{2} \underline{Y}_{y}}{\underline{Y}_{s}+\underline{Y}_{x}+\underline{Y}_{y}}
$$

Jeżeli uwzględnimy zależność między skuteczną wartością mocy a admitancją elementu układu, to możemy napisać:

$$
\begin{gathered}
\frac{\underline{U_{2}}}{\underline{U}_{l}}=-\frac{Y_{x}+a^{2} \underline{Y}_{y}}{\underline{Y}_{s}+\underline{Y}_{x}+\underline{Y}_{y}}=-\frac{\underline{Y}_{x} U_{l}^{2}+a^{2} \underline{Y}_{y} U_{l}^{2}}{\left(\underline{Y}_{s}+\underline{Y}_{x}+\underline{Y}_{y}\right) U_{l}^{2}}= \\
=-\frac{\underline{S}_{x}+a^{2} \underline{S}_{y}}{\underline{S}_{s}+\underline{S}_{x}+\underline{S}_{y}}
\end{gathered}
$$

gdzie $S_{S}$ jest mocą zwarciową układu zasilającego w miejscu przyłączenia transformatora.

Korzystając z równań opisujących moc poszczególnych uzwojeń strony wtórnej transformatora $\mathrm{w}$ zależności od mocy całkowitej transformatora oraz wykorzystując fakt, że moc zwarciowa systemu jest dużo razy większa od mocy transformatora trakcyjnego, to powyższe równanie przyjmuje postać: 


$$
\left.\frac{\underline{U}_{2}}{\underline{U}_{1}}=-\left(k \underline{S}_{T}+a^{2}(1-k)\right) \frac{\underline{S}_{T}}{\underline{S}_{s}}\right) \cong-\sqrt{3 k^{2}-3 k+1} \frac{\underline{S}_{T}}{\underline{S}_{s}}
$$

Jak wynika z powyższego równania współczynnik asymetrii napięć $\varepsilon_{u}$ jest iloczynem współczynnika szybkości przekazywania energii przez transformator oraz stosunku skutecznych wartości moca transformatora i mocy zwarciowej systemu w miejscu zasilania:

$$
\varepsilon_{u}=k_{f} \frac{S_{T}}{S_{k}} 100 \%
$$

Występujący w powyższym wzorze współczynnik $k_{f}$ ma wartość równą jeden w przypadku, gdy napięcia zasilające sieć trakcyjną są przesunięte względem siebie o kąt $180^{\circ}$. Jeżeli przesunięcie fazowe napięć zasilających po stronie wtórnej jest równe $120^{\circ}$, to współczynnik $k_{f}$ obliczamy według następującego wzoru:

$$
k_{f}=\sqrt{3 k^{2}-3 k+1}
$$

W przypadku przesunięcia napięć o $90^{\circ}$ wartość współczynnika $k_{f}$ jest obliczana zgodnie ze wzorem:

$$
k_{f}=|2 k-1|
$$

Jak wynika z powyższych zależności o wartość współczynnika niesymetrii napięć decyduje przede wszystkim wartość mocy zwarciowej w podstacji trakcyjnej. Dużo mniejszy wpływ ma rozkład mocy i przesunięcia fazowego między napięciami zasilającymi trakcję kolejową. $\mathrm{Na}$ rys. 2 przedstawiono wpływ rozkładu mocy między fazami strony wtórnej transformatorów na wartość współczynnika niesymetrii dla różnych układów połączeń uzwojeń transformatorów.

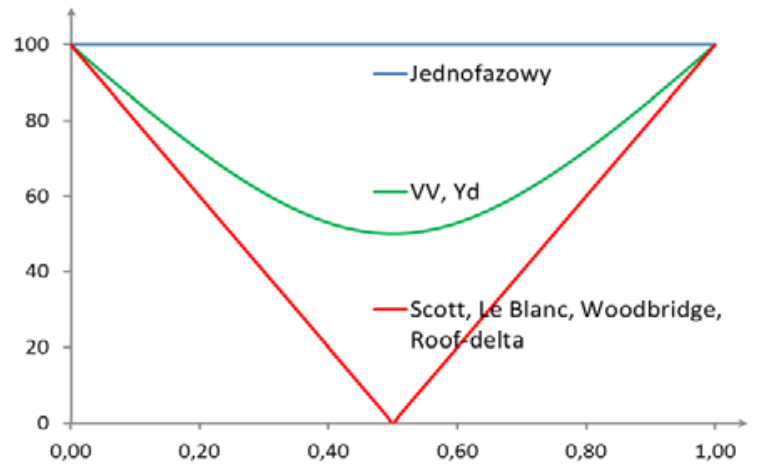

Rys. 1. Względne wartości wspótczynnika niesymetrii napięć

\section{Posumowanie}

Opisane w artykule układy połączeń transformatorów można w zależności od kąta przesunięcia fazowego napięć strony wtórnej oraz funkcji opisującej zmiany współczynnika szybkości przekazywania energii podzielić na trzy klasy. Do pierwszej klasy należą transformatory o przesunięciu fazowym napięć równym 0 lub $\pi$. W tym przypadku stopień obciążenia poszczególnych uzwojeń wtórnych $K$ nie wpływa na wartość współczynnika szybkości przekazywania energii. Do klasy drugiej zaliczamy transformatory, w których kąt przesunięcia między napięciami strony wtórnej jest wielokrotnością kąta $\pi / 3$. Do klasy trzeciej należą transformatory o kącie przesunięcia faz strony wtórnej równym $\pi / 2$. Współczynnik szybkości przekazywania energii dla tej klasy transformatorów ma największą wartość w całym zakresie zmienności obciążenia, co świadczy o dużej zdolności thumienia niesymetrii obciążeń przez taki transformator.

Dokonując wyboru sposobu zasilania układów trakcji kolei dużych prędkości należy dążyć do wyboru takiego układu połączeń, aby spełnić wymagania określone w Instrukcji Ruchu i Eksploatacji Krajowego Systemu Energetycznego. Przyjmując, że moc typowej podstacja trakcyjnej kolei dużych prędkości wynosi $60 \mathrm{MVA}$, to przy dopuszczalnej wartości współczynnika asymetrii napięć zasilających $1 \%$ moc zwarciowa systemu powinna być powyżej 6 GVA. W Krajowym Systemie Energetycznym takie wartość mocy zwarciowej występuje jedynie w sieciach o napięciu $400 \mathrm{kV}$. Wybór poziomu napięć zasilających oraz zastosowanie konkretnego układu połączeń uzwojeń transformatora ma zasadniczy wpływ na decyzję o zastosowaniu lub nie dodatkowych układów kompensujących chwilowe zmiany napięć w sieci zasilającej. Oczywiście istotnym aspektem przy wyborze sposobu zasilania trakcji kolejowej są koszty produkcji, instalacji i eksploatacji poszczególnych transformatorów.

\section{BIBLIOGRAFIA}

[1] Burchi G., Lazaroiu C., Golovanov N., Roscia M.: Estimation of Voltage Unbalance in Power Systems Supplying High Speed Railway, Electrical Power Quality and Utilisation, Vol. XI, No. 2, pp. 113-119, 2005.

[2] Sutherland P. E., Waclawiak M., McGranaghan M. F.; Analysis of Harmonics, Flicker and Unbalance of TimeVarying Single-Phase Traction Loads on a Three-Phase System, International Conference on Power Systems Transients, Canada, June 19-23, 2005.

[3] Morimoto H., Uzuka T,. Horiguchi A., Akita T.: New Type of Feeding Transformer for AC Railway Traction System, pp. 800-805, PEDS 2009.

[4] Ładniak L.: Transformacja napięć i pradów w ukladach zasilania trakcji kolei dużych prędkości, Transcomp XIV International Conference Computer Systems Aided Science, Industrial and Transport, Zakopane 2010. 